\title{
Cultivo experimental de Octopus mimus, Gould 1852 en el Perú
}

\author{
Experimental culture of Octopus mimus, Gould 1852 in Peru
}

\author{
Paul Baltazar, Pilar Rodríguez, William Rivera y Violeta Valdivieso *
}

\section{RESUMEN}

Octopus mimus Gould, 1852 es un recurso bentónico muy importante en la pesquería artesanal peruana y de gran demanda en el mercado internacional. Aclualmente no existen anlecedentes sobre el cultivo de esta especie en el Pacifico Sudeste, salvo los realizados por Zuñiga $(1995,1996$ a, b) y Baltazar et al. (1999).

Las experiencias de cultivo se realizaron en las instalaciones del Centro de Acuicultura La Arena, Casma, Perú, empleándose tanques de fibra de vidrio y long-line en el mar La alimentación fue a base de peces, crustáceos y moluscos, se ensayó con pienso húmedo que fue aceptado tras un periodo de inanición. La cópula se realizó con ejemplares mayores a $1,5 \mathrm{~kg}$.

Se observó diferencias en el crecimiento, en los tanques (185 y $369 \mathrm{~g} / \mathrm{mes}$ ) fue mayor que en las lineas de cultivo $(120,6 \mathrm{~g} / \mathrm{mes})$. Se obtuvieron paralarvas con una supervivencia máxima de 17 días a temperaturas de 21 a $22{ }^{\circ} \mathrm{C}$, las que fueron alimentadas con nauplios de artemia (camarón de salmuera).

Palabras clave: Octopus, cultivo, crecimiento, reproducción, paralarva.

\section{ABSTRACT}

Octopus mimus Gould, 1852 is an important benthic resource in the Peruvian artisanal fishery and is always in demand on the international market. Bibliographic antecedents about the culture of this species for Southeastern Pacific are few.

The present study was made in the Center of Aquaculture "La Arena", Casma, Peru. The experiments were carried out in fiber glass tanks and long-line in the sea. Feeding was made with fish, crustaceans and mollusk and also was tested with wet pellets ("piensos humedos"), the last one being accepted after an starvation period. For copulation the biggest specimens were chosen (1,5 kg). Differences were observed in growth for those reared in the pools (185 and $369 \mathrm{~g} / \mathrm{month}$ ), the growth rate was greater than that of those in the lines of culture $(120,6 \mathrm{~g} / \mathrm{month})$. The maximum paralarvae survival was 17 days to temperatures of 21 to $22{ }^{\circ} \mathrm{C}$; they were fed with nauplios of brine shrimp.

Key words: Octopus, culture, growth, reproduction, paralarvae.

\section{INTRODUCCIÓN}

El pulpo (Octopus mimus Gould, 1852) es un recurso potencial para un futuro cultivo comercial en el Perú, debido a que presenta similares características que $O$. vulgaris (Nixon, 1969; Mangold, 1983): ciclo de vida corto, elevadas tasas de crecimiento, se

\footnotetext{
- Fondo Nacional de Desarrollo Pecquero (FONDEPES) Gerencia de Acuicultura. Av. Petil Thouars N. 115. Lima 1. Peru. E-mail fondepes@lerra compe
}

adaptan fácilmente y se reproducen en cautiverio, aceptan una gran variedad de alimentos (vivos, congelados, piensos húmedos, etc.) y alcanzan altos precios en el mercado nacional e internacional.

Actualmente existen pocos estudios sobre el cultivo de O. mimus (Zuñiga, 1995, 1996 a b; Olivares, 1996; Cortez et al., 1999), sin embargo para otras especies de Octopus existe considerable información (Itami et al, 
1963; Nixon, 1966; Robaina, 1979, 1983; Forsythe \& Hanlon 1980, 1981; Hanlon \& Hixon, 1982; Boletzky \& Hanlon, 1983; 1985; Hanlon, 1983 a, b; Mangold, 1983 b; Hanlon \& Forsythe, 1985; Boyle, 1991; Villanueva, 1994, 1995: Iglesias, 1996, 1997. 1997; Rama - Villar, et al 1997).

En el Perú los estudios sobre el ciclo de vida, ecología y biología de $O$. mimus son escasos (Cardoso et al., 1999; Villegas y Tafur, 1999), y no existen antecedentes sobre el cultivo de esta especie (Baltazar et al., 1999).

Desde 1998 el Fondo Nacional de Desarrollo Pesquero (FONDEPES) viene realizando investigaciones sobre el cultivo de O. mimus en los Centros Acuícolas La Arena (Áncash) y Morro Sama (Tacna). Los objetivos planteados fueron establecer los requerimientos de la reproducción, crecimiento, y alimentación de $O$. mimus en diferentes condiciones de cultivo, con la finalidad de diseñar una tecnología de cultivo de esta especie, que permita una diversificación de la maricultura en el Perú.

\section{MATERIAL Y MÉTODOS}

Entre mayo de 1998 y marzo de 1999 se colectaron un total de 100 ejemplares de $O$. mimus en las zonas costeras próximas a los Centros de Acuicultura La Arena y Morro Sama.

El objetivo de los experimentos fue determinar las diferencias de crecimiento entre los tanques y jaulas instalados en un long line, por lo que no se consideraron las diferencias sexuales; la distribucion de los ejemplares se hizo al azar sin considerar el sexo. Los ejemplares fueron separados en dos grandes grupos para realizar experimentos de cultivo en tanques (Grupo 1) y en líneas de cultivo (Grupos 2 y 3 ) situadas en el mar, como se describe a continuación:

\section{a) Cultivo en tanques}

50 ejemplares fueron mantenidos en tanques rectangulares de fibra de vidrio de $1 \mathrm{~m}^{3}$, con un flujo de agua semicontinuo de $1,5 \mathrm{l} / \mathrm{mi}$ nuto. Los tanques fueron cubiertos con una malla negra de $5 \mathrm{~mm}$ de diámetro para mantenerlos en la penumbra y evitar la fuga de los pulpos. Inicialmente como refugios se utilizaron tubos de PVC (largo $30 \mathrm{~cm}$ y $25 \mathrm{~cm}$ de diámetro), posteriormente se colocaron individualmente en bidones plásticos de polipropileno previamente perforados en su base para permitir suficiente aireación.

Los ejemplares se dividicron en dos grupos según su peso: el primer grupo, compuesto de 20 ejemplares, con una media de $22,2 \pm 8,3 \mathrm{~g}$ y una densidad inicial de cultivo de $0,44 \mathrm{~kg} / \mathrm{m}^{3}$, y el segundo grupo, compuesto de 30 ejem-plares, con una media de $347,9 \pm$ $91,8 \mathrm{~g}$ y una densidad inicial de cultivo de $10,44 \mathrm{~kg} / \mathrm{m}^{3}$.

La temperatura del agua osciló duranti todo el período de estudio entre 17 y $21^{\circ} \mathrm{C}$ con una media de $18,95 \pm 0,91^{\circ} \mathrm{C}$ y valores de oxígeno entre 4 y $8 \mathrm{ml} / \mathrm{l}$.

\section{b) Cultivo en líneas}

50 ejemplares fueron trasladados a una línea de cultivo, los cuales se colocaron en 10 cuelgas con 10 refugios de PVC (largo $30 \mathrm{~cm}$ y $25 \mathrm{~cm}$ de diámetro), abierto en uno de los extremos y con una tapa provista de una bisagra con el fin de poder observar y alimentar a los animales. El peso medio inicial fue de $117,5 \pm 25,7$ g. y a una densidad de $0,705 \mathrm{k} /$ cuelga.

\section{Alimentación}

Para ambos experimentos la alimentación consistió en dietas naturales vivas y congeladas como crustáceos $56 \%$ (Pinnotheria laevigata, Callinectes arcuatus y majidae), moluscos 33\% (Semele solida, Perumytilus purpuratus, Pteria sterna y Crucibulum spinosum) y peces $11 \%$ 
(Odontesthes regia regia, Symphurus sechurae, Pseudupeneus grandisquamis, Umbrina xanty y Calamus brachysomus), el alimento fue suministrado ad libitum, y adicionalmente se realizaron ensayos con pienso húmedo (proteínas $37 \%$, grasas $10 \%$, cenizas $9 \%$ y humedad $44 \%$ ).

\section{Reproducción}

De los cultivos de tanques se separaron 12 hembras y 12 machos con pesos entre 1517 y $1803 \mathrm{~g}$ ( $1660 \pm 202 \mathrm{~g})$. En un tanque de $200 \mathrm{~L}$ se pusieron una hembra y un macho para realizar la cópula; posteriormente las hembras fecundadas se trasladaron a tanques rectangulares de $1 \mathrm{~m}^{3}$ con temperaturas entre 17 y $22^{\circ} \mathrm{C}\left(17,25 \pm 0,55^{\circ} \mathrm{C}\right)$ y valores de oxígeno entre 4 y $8 \mathrm{ml} / \mathrm{l}$. Los tanques fueron cubiertos con una malla negra de $5 \mathrm{~mm}$ de diámetro. Una vez obtenidas las puestas, se registró la duración del desarrollo embrionario de cada puesta, se contabilizó el número total de cordones de huevos y el número de huevos por cada cordón; asimismo se estimó la tasa de eclosión y fecundidad.

\section{Procesamiento y análisis de los datos}

Se realizaron muestreos mensuales de los cultivos considerando el número de ejemplares y peso de cada uno de ellos. Se calculó:

- Tasa de crecimiento instantáneo en peso:

$\mathrm{G} W=\left[\mathrm{Ln} W f-\mathrm{Ln} W \mathrm{Wi} / \mathrm{N}^{\circ}\right.$ días $] * 100$

Donde:

GW = Tasa de Crecimiento Instantaneo en Peso

$W i=$ Peso inicial

$W f=$ Pesofinal

- Tasa absoluta de crecimiento instantáneo en peso.

$\mathrm{TCla}=\mathrm{Wf}-\mathrm{Wi} / \mathrm{N}^{\circ}$ días

Donde:

TCla = Tasa Absoluta de Crecimiento Instantáneo

$W i=$ Peso inicial

$W f=$ Peso final
- Tasa de conversión alimenticia.

TCA = Alimento ingerido/Incremento en peso Donde:

$\mathrm{Wi}=$ Pesoinicial

$W f=$ Peso final.

Se determinó el tipo de función matemática que más se ajustaba a la relación peso ( $\mathrm{g}$ ) tiempo (meses) y la tasa de crecimiento instantáneo-tiempo.

Cultivo de paralarvas. Las paralarvas obte nidas fueron colocadas en tanques circulares de $200 \mathrm{~L}$ a temperaturas de 21 a $22{ }^{\circ} \mathrm{C}$ y valores de oxigeno entre 4 y $8 \mathrm{ml} / \mathrm{l}$ y con un flujo de aireación lento. Las paralarvas fueron sembradas a una densidad de 50 ejemplares/l, diariamente se renovaba el 100\% del agua La alimentación fue a base de nauplios de Artemia (5 nauplios $/ \mathrm{ml}$ ) y de microalgas (Chaetoceros sp., Isocrysis sp. y Dunaliella sp.).

\section{RESULTADOS Y DISCUSIÓN}

\section{Crecimiento en tanques}

Los pulpos (Octopus mimus) crecieron de $22,2 \mathrm{~g}$ a $1133,3 \mathrm{~g}$ en 6 meses de cultivo (grupo 1) y de $347,9 \mathrm{~g}$ a $2188,7 \mathrm{~g}$ en 5 meses de cultivo (grupo 2). La función que mejor se ajustó a la relación del peso-tiempo sigue una curva de tipo exponencial (Fig. 1):

Grupo $1 \quad W=42,263 e^{(1) .60011}\left(r^{2}=0,92\right)$

Grupo $2 W=434,74 e^{0.35771} \quad\left(r^{2}=0,95\right)$

Los parámetros determinados en el crecimiento quedan resumidas en la tabla 1 . Para ambos grupos se aprecia una disminución del índice de crecimiento instantáneo en peso (Fig. 2), en función del tiempo de engorde, desde $5,52 \%$ a $0,82 \%$, con una media de $2.18 \%$ (grupo 1) y desde $2,28 \%$ a $0,54 \%$, con una media de $1,23 \%$ (grupo 2).

La tasa absoluta de crecimiento instantáneo (tabla 1) tuvo valores que aumentaron en función del tiempo. Los pulpos 
a medida que aumentaron de peso, también incrementaron la ganancia en peso por día. El primer grupo aumentó desde 1,61 g/día hasta $12,75 \mathrm{~g} /$ día, con una ganancia total media de $6,17 \mathrm{~g} /$ día; y el segundo grupo desde $10,9 \mathrm{~g} /$ día hasta 14,4 g/día, con una media de 12,27 $\mathrm{g} /$ día. Se registro un $5 \%$ de mortalidad en el grupo 1, coincidiendo con el primer mes de adaptación al cautiverio. La densidad final de cultivo para el primer grupo fue de $22,67 \mathrm{~kg}$ / $\mathrm{m}^{3}$ y para el segundo grupo de $65,66 \mathrm{~kg} / \mathrm{m}^{3}$ (Tabla 1).

\section{Crecimiento en líneas}

Los pulpos (Octopus mimus) crecieron de $117,5 \mathrm{~g}$ a $721,2 \mathrm{~g}$ en 5 meses de cultivo. La función que mejor se ajusó a la relación del peso-tiempo de engorde sigue una curva de tipo exponencial:

$W=88,202 e^{(1) .4379)}\left(r^{2}=0,97\right)$
Los parámetros determinados en el crecimiento quedan resumidos en la Tabla 1. Al igual que en el engorde en tanques, se aprecia una disminución del índice de crecimiento instantáneo en peso en función del tiempo de cultivo, desde $2,43 \%$ a $1,12 \%$, con una media de 1,21.

O. mimus, bajo las condiciones señaladas, tiene un crecimiento de $0,72,1,13$ y $2,18 \mathrm{~kg}$ en 5 y 6 meses, respectivamente. Las tasas de crecimiento fueron mayores en el cultivo en tanques y menores en las líneas de cultivo. Estos bajos crecimientos se deberían posiblemente a que los animales se encontrarían estresados por acción del movimiento de las corrientes, y/o por encontrarse en substrato suspendido, muy ajeno a su hábitat bentónico.

Aunque es posible efectuar comparaciones con tasas de crecimiento de otras especies de

Tabla 1. Tasas de crecimiento instantáneo (GW), tasas de conversión alimenticia (TCA), tasa absoluta de crecimiento instantáneo (TCla) y mortalidad total ( $\mathrm{Z}$ ) de dos grupos de Octopus mimus en estanques y líneas de cultivo

\begin{tabular}{cccc}
\hline & \multicolumn{2}{c}{ Estanques } & Líneas \\
\cline { 2 - 3 } & Grupo 1 & Grupo 2 & 50 \\
Número & 20 & 30 & 5 \\
Tiempo (meses) & 6 & 5 & $117,5 \pm 25,7$ \\
Peso inicial $(\mathrm{g})$ & $22,2 \pm 8,3$ & $347,9 \pm 91,8$ & $721,2 \pm 140,3$ \\
Peso final $(\mathrm{g})$ & $1133,3 \pm 216,9$ & $2188,7 \pm 322,6$ & 0,705 \\
Densidad inicial $\left(\mathrm{k} / \mathrm{m}^{3}\right)$ & 0,44 & 10,44 & 34,62 \\
Densidad final $\left(\mathrm{k} / \mathrm{m}^{3}\right)$ & 22,67 & 65,66 & 4,1 \\
TCA & 2,89 & 3,79 & 4,02 \\
TCla & 6,17 & 12,27 & 1,21 \\
GW $(\%)$ & 2,18 & 1,23 & 20 \\
Z $(\%)$ & 5 & 0 & \\
\hline
\end{tabular}


Octopus en cultivo, hay que tener en cuenta las diferentes condiciones en cada caso. Las tasas de crecimiento han sido menores que las reportadas para $O$. vulgaris (Iglesias et al., 1996, 1999). Debe señalarse que el tamaño de los refugios, la densidad de carga, el confinamiento, los recambios de agua, acción de la corriente, la manipulación continua y una posible inadecuada nutrición, pueden ser algunos de los factores que limiten la tasa de crecimiento de esta especie. Se espera mejores resultados de crecimiento cuando: (i) se críen en tanques de mayor capacidad, (ii) en circuito abierto, (iii) la manipulación de los ejemplares sea mínima y (iv) el tipo de alimentación sea la más adecuada para la especie.

\section{Alimentación}

Aunque la alimentación se basó en dietas de animales vivos y congelados, también aceptaron piensos húmedos, sólo cuando no se les alimentó con presas vivas, quedando aún por realizar más ensayos de nutrición para acelerar el crecimiento en cultivo. En el engorde en estanques la tasa de conversión alimenticia obtenida para el primer grupo fue de 2,89 y para el segundo grupo de 3,79 , y en el engorde en líneas fue de 4,1.

\section{Reproducción}

Cópula. Durante la cópula el macho mantiene una corta distancia de la hembra y extiende el tercer brazo derecho, que posee el hectocótilo, para introducir los espermátoioros en los oviductos distalis de la hembra. Lus primeras puestas para un grupo se dieron a los 8 días y para otro a los 38 días, durando alrededor de 15 días en promedio para cada caso.

Puesta. La hembra durante la puesta y la incubación deja de alimentarse. Los cordones de huevos fueron colocados en las paredes del estanque y en todo momento las hembras los protegieron con los brazos. Ellas constantemente airean con el sifón y las puntas de los brazos, y limpian de epizoos hasta antes de la eclosión. Cuando los huevos no son cuidados por la hembra, se contaminan llenándose de protozoos coloniales (Vorticella

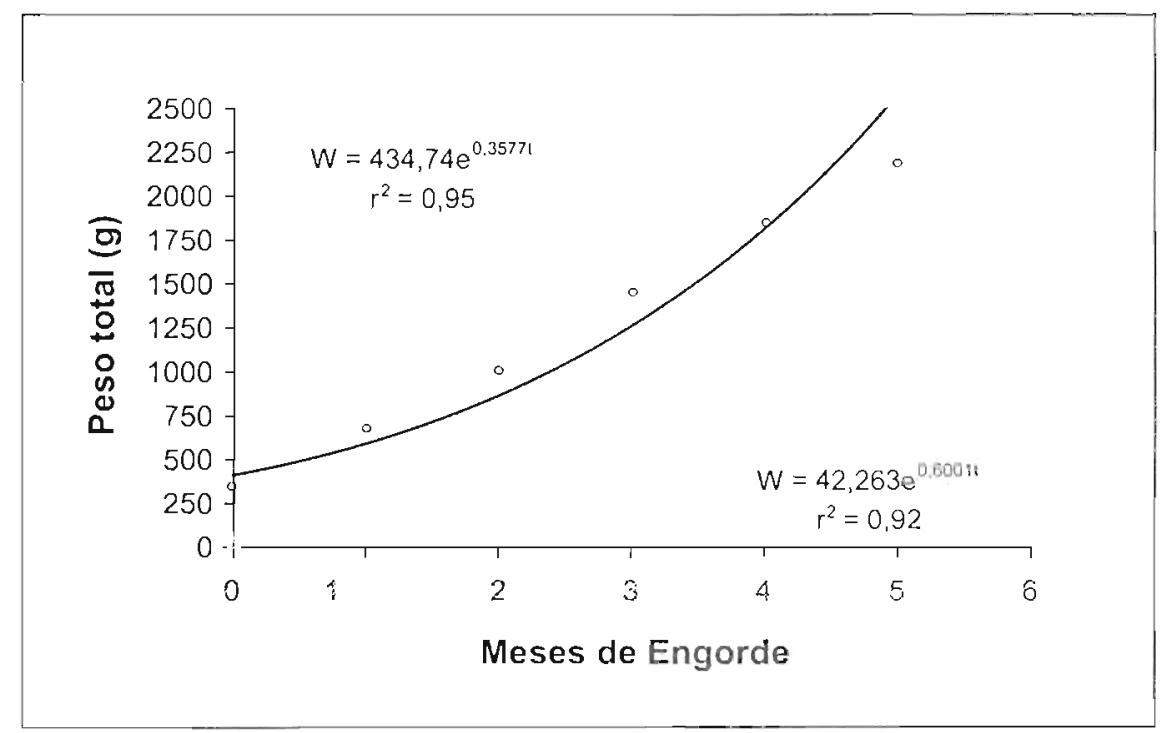

Fig. 1 Crecimiento en peso de Octopus mimusen estanques rectangulares: Grupo 1 (triángulos) y grupo 2 (circulos). 
sp.) y propagulos de algas (Ulva sp.), no siendo viables posteriormente (Baltazar et al., 1999).

Los huevos. Se encuentran fijados al racimo mediante un pedúnculo y están unidos a un cordón central. Las características y los paránetros biométricos de los racimos, los huevos y paralarvas recién nacidas se muestran en la rabla 2.

El desarrollo embrionario. Duró alrededor de 25 días. Pocos días después de la eclosión, las hembras murieron, perdiendo entre el 45 al $60 \%$ de su peso total con respecto al que tenían al inicio de la puesta. La disminución del peso se explicaría porque los ejemplares dejaron de alimentarse, lo cual implica un gran desgaste energético en el proceso reproductivo.

Las primeras paralarvas para un grupo eclosionaron a los 37 días después de iniciada la puesta, con temperaturas de $22 \pm 0,63^{\circ} \mathrm{C}$ y a los 45 días para otro grupo a temperaturas de $19,2 \pm 0,42^{\circ} \mathrm{C}$, observándose que el tiempo de desarrollo embrionario disminuye con el incremento de temperatura, resultados que también han sido obtenidos por otros investigadores para $O$. mimus y $O$. vulgaris (Zuñiga. 1995, 1996b; Olivares et al., 1996; Iglesias, (997).

O. mimus se acondicionó y adaptó fácilmente al cautiverio, lográndose un 100\% de hembras con puestas de huevos e incubación. Obteniéndose un 95,5\% de eclosión a temperaturas de 19 y $22{ }^{\circ} \mathrm{C}$. Zuñiga et al. (1995) sostienen que la luz es uno de.los factores principales que regula la reproducción en los cefalópodos, y que en $O$. mimus la condición de penumbra, la glándula óptica promovería a la síntesis y secreción de una proteína de efectos gonadotrópicos la cual promueve la maduración sexual en esta

Tabla 2. Características y datos biométricos de hembras incubantes y puestas de Octopus mimus de cultivo

\begin{tabular}{ll}
\hline Número total de hembras & 12 \\
Número total de puestas & 12 \\
Peso hembras al inicio de la puesta & $1517-1803 \mathrm{~g}$ \\
Peso hembras al final de la incubación & $682-1081 \mathrm{~g}$ \\
Periodo de puesta & noviembre, diciembre, febrero \\
Duración del desanollo embrionario & $37-45$ dias $\left(22-19^{\circ} \mathrm{C}\right)$ \\
Número de racimos/puesta & $362-380$ \\
Número de huevos/cordón & $320-1800$ \\
Longitud del racimo & $14,9-91,8 \mathrm{~mm}$ \\
Longitud del huevo en la puesta & $1,9-2,5 \mathrm{~mm}(2,2 \pm 0,2)$ \\
Longitud del huevo al eclosionar & $2,1-3,0 \mathrm{~mm}(2,5 \pm 0,3)$ \\
Longitud lo lal de la paralarva (0 dias) & $1,8-2,2 \mathrm{~mm}(1,9 \pm 0,1)$ \\
Longitud del manto de la paralana (0 dias) & $0,90-1,2 \mathrm{~mm}(0,98 \pm 0,2)$ \\
Peso de la paralarva (0 dias) & $0,001 \pm 0,0001 \mathrm{~g}$ \\
Peso del racimo & $1,1 \pm 0,4 \mathrm{~g}$ \\
\hline
\end{tabular}


especie y que más bien la temperatura no influiría relevantemente como ha sido demostrado para otros Octopus (Smale \& Buchan, 1981).

Las paralarvas son planctónicas y presentan un fototactismo positivo; mantienen la orientación del cuerpo en un ángulo agudo con la cabeza hacia abajo. La talla al eclosionar de la paralarva fue $2,2 \pm 0,2 \mathrm{~mm}$ de longitud total y $0,99 \pm 0,2 \mathrm{~mm}$ de longitud manto. No presentan estadios larvales, ni metamorfosis situación de gran ayuda en los cultivos, dado que se obtienen pulpos que se asemejan a los adultos (Robaina, 1983; Zuñiga, et al. 1996 b; Baltazar, obs. pers.)

Las hembras de Octopus son capaces de desovar entre 5000 a 605000 huevos (Mangold, 1983; Robaina, 1983; Forsythe \& Hanlon, 1985; Villanueva, 1995; Iglesias, 1997), encontrándose para $O$. mimus en experiencias chilenas entre 80000 y 400000 huevos (Zuñiga et al., 1996 a) y en nuestro trabajo reportamos un máximo de 432440 huevos /puesta.

\section{Cultivo de paralarvas}

Las larvas fueron alimentadas con nauplios de Artemia, y se obtuvo un máximo de supervivencia de 17 días. Las mayores mortalidades (90\%) se presentaron entre el cuarto y quinto día, momento en el cual la reserva ha sido totalmente absorbida por la paralarva.

La supervivencia de las paralarvas de $O$. mimus fue inferior a la obtenida por Zuñiga (I996) para la misma crpecie y para O. vulgaris (Villanueva, 1994; Iglesias, 1997). Estos últimos investigadores lograron mayores supervivencias cuando las paralarvas d. $O$ vulgaris fueron alimentadas con artemias enriquecidas con ácidos grasos poliinsaturados y con zoeas de crustáceos. El cultivo de las paralarvas de $O$. mimus hasta ahora es un poco dificultoso y se requiere realizar más ensayos para solucionar principalmente los problemas nutricionales.

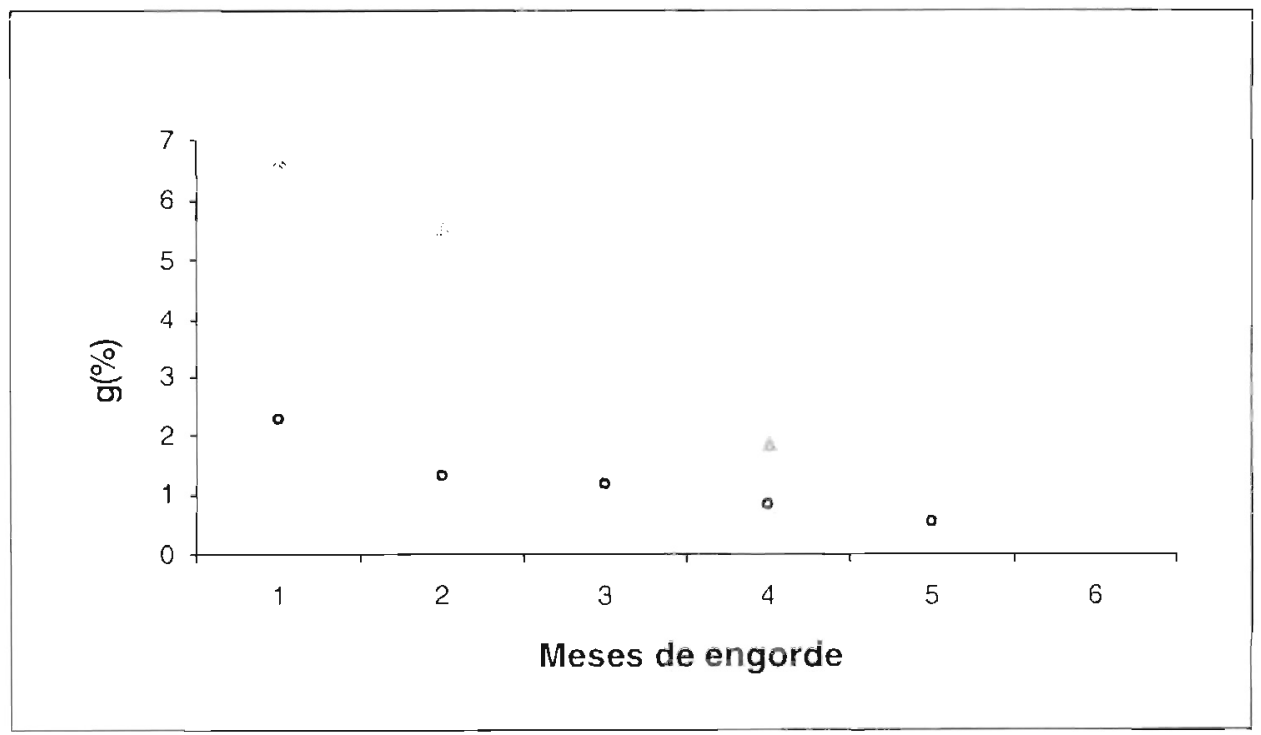

Fig. 2 Variación de la tasa de crecimiento instantáneo en peso (g) de Octopus mimus en estanques rectangulares: grupo 1 (triángulos) y grupo 2 (círculos). 


\section{CONCLUSIONES}

- El engorde de juveniles de Octopus mimus en tanques y por separado muestra altas tasas de crecimiento (185 y $369 \mathrm{~g} / \mathrm{mes}$ ), utilizando alimento vivo, congelado y pienso húmedo, pudiéndose obtener tallas comerciales de 1,1 y $2,2 \mathrm{~kg}$ en un período de 5 a 6 meses de engorde con tasas de mortalidad muy bajas ( $5 \%$ ).

- El engorde en líneas de cultivo no sería uno de los sistemas más adecuados para realizar el engorde de $O$. mimus, dado que las tasas de crecimiento son más lentas (120,6 g/mes) y presentan mayores mortalidades $(20 \%)$.

- Los ejemplares juveniles y subadultos tras un período de inanición aceptaron piensos húmedos, quedando aún por realizar más ensayos a este respecto.

- En condiciones de cautiverio el 100\% de hembras fueron fecundadas y se obtuvieron puestas de buena calidad con altos índices de eclosión $(95,5 \%)$, en situación de penumbra.

- En el cultivo de las paralarvas se obtuvieron altas mortalidades, principalmente debido a la falta de una buena nutrición, obteniéndose una supervivencia máxima de 17 días.

\section{AGRADECIMIENTOS}

En especial al Dr. Rogger Villanueva por la revisión del manuscrito y al Blgo. Franz Cardoso por sus critcas y comentarios. Se agradece el financiamiento del FONDEPES para el desarrollo de la presente investigación.

\section{LITERATURA CITADA}

Baltazar, P., F. Cardoso y V. Valdivieso. 1999. Observaciones preliminares sobre el cultivo de pulpo Octopus mimus (Cephalopoda: Octopoda) en el Perú. En: Libro de resúmenes del VIII Congreso Latinoamericano de Ciencias del Mar.

Boletzky, S.y R. Hanlon. 1983. A review of laboratory maintenance, rearing and culture of cephalopod molluscs. Nem. Nat. Mus. Victoria 44: 147 187.

Cardoso, F., C. Paredes y R. Tafur. 1999 Aspectos reproductivos y pesqueros de Octopus mimus (Cephalopoda: Octopoda) en Ilo durante El Niño 1991/93. En: VIII Reunión Científica ICBAR, Libro de Resúmenes: 126.

Cortez, T., A. González y A. Guerra. 1999. Growth of cultured Octopus mimus (Cephalopoda, Octopodidae). Fisheries Research 40: 81-89.

Forsythe, J. y R. Hanlon. 1980. A closed marine culture system for rearing $O c$ topus joubini and other large egged benthic octopods. Lab. Anim. Sci. 14: 137-142.

Forsythe, J. y R. Hanlon. 1981. First rearing of Octopus joubini and robson on mysidacean caridean shrimps. Bull. Am. Mal. Union 42-45.

Hanlon, R. 1983a. Octopus joubini. In: P.R. BOYLE (ed.). Cephalopod life cycles, Vol I. Academic Press. London, pp. 293-310. 
Hanlon R. 1983b. Octopus briaeus. In: P. R. BOYLE (ed.). Cephalopod life cycles, Vol I. Academic Press. London, pp. 251-266.

Hanlon, R. y J. Forsythe. 1985. Advances in the laboratory culture of octopuses for biomedical research. Lab. Anim. Sci. 35: 33-40.

Hanlon, R. y R. Hixon. 1982. Laboratory maintenance and culture of octopuses and loliginid squid. Vol. 4. The Marine Biomedical Inst. Univ. Texas, 4: 44-60.

Iglesias, J., F. Sánchez, y J. Otero. 1996. The Octopus (Octopus vulgaris, Cuvier): a candidate for aquaculture? ICES C.M. 1996/F: 10.

Iglesias, J., F. Sánchez, y J. Otero. 1997. Primeras experiencias sobre el cultivo integral del pulpo (Octopus vulgaris) en el Instituto Español de Oceanografía. En: Actas del VII Congreso Nac. de Acuicultura, Cartagena. Costa J., Abellan E., García B., Ortega A. y Zamara S. (eds.). ISBN: 84-491-0323; 221-226 pp.

Iglesias, J., F. Sanchez, y J. Otero. 1999. Culture of (Octopus vilgaris, Cuvier): present knowledge, problems and perspectives. En: Conferencia en el Taller Acuicultura Sostenible: "Desarrollo y Comercio". Lima 911 junio 1999. Ministerio de la Presidencia, p. 11.

Itami, K., Y. Izawa, S. Maeda y K. Nakai. 1963. Notes on the laboratory culture of the Octopus larvae. Bull. Jap. Soc. Sci. Fish. 29(6): 514-520.

Mangold, K. 1983a. Food, feeding and growth in cephalopods. Mem. Nat. Mus. Victoria 4: 81-93.
Mangold, K. 1983. Octopus vulgaris. In: P. R. BOYLE (ed.). Cephalopod life cycles, Vol I. Academic Press. London, pp. 335-364.

Nixon, M. 1966. Changes on body weight and intake of food by Octopus vulgaris. J. Zool. Lond. 150: 1-9.

Nixon, M. 1969. The life span of Octopus vulgaris i.amarck. Proc. Malacol. Soc. T, ond. 38: 529-540.

Olivares, A., O. Luñiga, G. Castro, C. Segura y J. Sanchez. 1996. Bases biológicas para el manejo de Octopus mimus: reproducción y crecimiento. Estud. Oceanol. 15:61-74.

Rama-villar, A., V. Faya, C. Moxica y M. ReyMendez. 1997. Engorde de pulpo (Octopus vulgaris) en batea. En: Actas del VII Congreso Nacional de Acuicultura, Cartagena. Costa J., Abellan E., García B., Ortega A. y Zamara S. (eds.). ISBN: 84-4910323-1, pp. 221-226.

Robaina, G. 1979. Contribución al cultivo de los cefalópodos decapodos. Lagena N. ${ }^{\circ} 43-44: 55-62$

Robaina, G. 1983.Algunos a:pectos sobre el cultivo de lu: moluscos cefalópodos octópodos. Rev. Lat. Acui. N. ${ }^{\circ} 6$ : $1-42$.

Sánchez, F., J. Iglesias, C. Moxica y J. Otero. 1998. Growth of Octopus (Octopus vulgaris) male and female under culture conditions. ICES. CM. 1998/M: 17

Villanueva, R. 1994. Decapod crab zoeae as food for rearing cephalopod paralarvae. Aquaculture 128: 143152. 
Villanueva, R. 1995. Experimental rearing and growth of planktonic Octopus vulgaris from hatching to settlement. Can. J. Fish. Aquat. Sci. 52: 26392650 .

Villegas, P. y R. TAFUR. 1999. Talla de primera madurez y desove del pulpo (Octopus mimus) en el puerto del Callao. En: VIII Reunión Científica ICBAR, Libro de Resúmenes: 89.

Zuñiga, O,, A. Olivares y L. Ossandon. 1995. Influencia de la luz en la maduración sexual de hembras Octopus mimus. Est. Oceanol. 14: 75-76.
Zuñiga, O.. A. Olivares, E. Retamales y L. Ossandon. 1996a. Desarrollo de tecnología para la producción masiva de juveniles de pulpos, II región. En: Fondo de Investigaciones científicoTecnología de Universidades (19931994) FNDR Región de Antofagasta, pp. 57-66.

Zuñiga, O., A. Olivares y L. Muñoz. 1996 b. Resultados preliminares de la producción de larvas de pulpos $O_{c}$ topus mimus (II región, Chile). En: VII Congreso Latinoamericano sobre Ciencias del Mar, Libro de resúmenes: 567-569. 